\title{
Avaliação sensorial e composição centesimal de bolo adicionado de macroalga
}

O estilo de vida de nossa sociedade pode causar não apenas contaminação, mas também o esgotamento de diferentes recursos naturais. Neste contexto e em um planeta habitado por sete bilhões de pessoas, as escolhas alimentares tem papel fundamental para o desenvolvimento de práticas sustentáveis. Objetivou-se neste trabalho analisar as características sensoriais e a composição centesimal de um bolo preparado com a adição da macroalga Gracilaria birdiae (G. birdiae) em comparação com um bolo tradicional (controle). Amostras do bolo controle e do bolo G. birdiae foram submetidas a testes sensoriais para identificação de diferenças sensoriais, para medir a aceitação sensorial e a intenção de compra. Para verificar o valor nutricional, amostras da macroalga G. birdiae e dos bolos foram submetidas a análise de composição centesimal. Os provadores não identificaram diferença sensorial significativa $(p<0,05)$ entre as amostras. Não houve preferência para os atributos sensoriais odor e sabor, para textura e aparência global os provadores preferiram o bolo controle. O índice de aceitação foi acima de $70 \%$ para todos os atributos sensoriais de ambas as amostras e a intenção de compra foi maior para o bolo controle. A composição centesimal das macroalgas apresentou teores apropriados. Para os bolos não identificou-se diferença significativa $(p<0,05)$ na composição centesimal. Os resultados sensoriais são satisfatórios e permitem concluir que existe a possibilidade da adição da G. birdiae em bolo, porém nas condições estudadas não existe diferença significativa ( $p<$ $0,05)$ da composição centesimal.

Palavras-chave: Análise Sensorial; Composição Centesimal; Sustentabilidade; Gracilaria Birdiae.

\section{Sensorial assessment and centesimal composition of macroalga- added cake}

\begin{abstract}
The lifestyle of our society can cause not only contamination but also the depletion of different natural resources. In this context and on a planet inhabited by seven billion people, food choices play a key role in the development of sustainable practices. Current work analyzed the sensorial characteristics and the centesimal composition of a cake prepared with the addition of the macroalgae Gracilaria birdiae (G. birdiae) and compared to traditional cake (control). Samples of the control cake and the G. birdiae-added cake were submitted to sensorial tests to identify differences, to ascertain acceptance and purchase intention. Samples of macroalga G. birdiae and cakes were analyzed for centesimal composition to verify their nutritional value. Panelists failed to identify significant sensoria differences $(p<0.05)$ between samples. There was no preference for the odor and taste sensory attributes, panelists preferred control cake in the case of overall texture and appearance. Acceptance index was above $70 \%$ for all sensorial attributes of the two samples and whilst purchase intention was higher for control cake. The centesimal composition of the macroalgae presented adequate levels. No significant difference $(p<0.05)$ in centesimal composition was identified. Satisfactory sensorial results showed a possibility for supplementation by $G$. birdiae in the cake. However, under present conditions, no significant difference $(p<0.05)$ in the centesimal composition was extant.
\end{abstract}

Keywords: Sensory Analysis; Centesimal Composition; Sustainability; Gracilaria Birdiae.

Topic: Uso de Recursos Naturais

Reviewed anonymously in the process of blind peer.
Received: 10/02/2019

Approved: 25/03/2019
Tarcísio Augusto Gonçalves Júnior (iD

Universidade Federal do Rio Grande do Norte, Brasil http://lattes.cnpq.br/2569216883829122 http://orcid.org/0000-0003-0776-7848 tarcigastro@gmail.com

Dárlio Inácio Teixeira Alves

Universidade Federal do Rio Grande do Norte, Brasil http://lattes.cnpq.br/6835210577941969 darlioteixeira@gmail.com

\section{Cláudia Souza Macêdo (iD}

Universidade Federal do Rio Grande do Norte, Brasil http://lattes.cnpq.br/5335251554582575 http://orcid.org/0000-0002-3173-1821 claudiamacedo@hotmail.com
Cristiane Fernandes Assis

Universidade Federal do Rio Grande do Norte, Brasil http://lattes.cnpq.br/0034694007210837 cristianeassis@hotmail.com

José Hamilton Costa Filho (D)

Universidade Federal do Rio Grande do Norte, Brasil

http://lattes.cnpq.br/6461283056530144

http://orcid.org/0000-0001-5128-374X

hamilton costa@yahoo.com.br

Nkarthe Guerra Araújo (ic

Universidade Federal do Rio Grande do Norte, Brasil

http://lattes.cnpq.br/7360532168969595

http://orcid.org/0000-0002-6506-051X

nkarthe@gmail.com
Cibele Soares Pontes (iD)

Universidade Federal do Rio Grande do Norte, Brasil http://lattes.cnpq.br/7360532168969595 http://orcid.org/0000-0003-1993-0032 cibelepontes.ufrn@yahoo.com.br

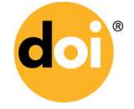

DOI: 10.6008/CBPC2179-6858.2019.002.0026
Referencing this:

GONÇALVES JÚNIOR, T. A.; ALVES, D. I. T.; MACÊDO, C. S.; ASSIS, C. F.; COSTA FILHO, J. H.; ARAÚJO, N. G.; PONTES, C. S.. Avaliação sensorial e composição centesimal de bolo adicionado de macroalga. Revista Ibero Americana de Ciências Ambientais, v.10, n.2, p.322-330, 2019. DOI: http://doi.org/10.6008/CBPC2179-6858.2019.002.0026 


\section{INTRODUÇÃO}

O estilo de vida da nossa sociedade e sua relação com a natureza podem causar não apenas contaminação, mas também o esgotamento de diferentes recursos naturais básicos para a vida humana. A pauta da sustentabilidade se torna relevante e urgente, destacando o debate sobre alternativas para minimizar o problema. Embora pesquisadores de diferentes áreas do conhecimento tenham elaborado várias teorias sobre sustentabilidade, o tema pode ter diferentes significados devido à ampla gama de conceitos, diferentes perspectivas e interpretações. No entanto, todos concordam que é importante buscar um equilíbrio entre as necessidades humanas e o meio ambiente, aliado a busca de entendimento sobre as dinâmicas de interação (BARBOSA et al., 2014).

Os sistemas alimentares têm um papel importante na vida humana e no meio ambiente. O desafio será maior para produzir alimentos de forma sustentável na esteira das previsões em relação à população mundial que chegará a nove bilhões de pessoas em 2050 (CONTE et al., 2013). Devido a novos padrões de consumo afetados pela industrialização, urbanização e globalização, diversas transformações influenciaram o estilo de vida humano e as escolhas alimentares da população (BRASIL, 2014). A variedade de ingredientes para produção de alimentos diminuiu durante os últimos cem anos (KINUPP et al., 2014).

$\mathrm{O}$ atual sistema de exploração de produtos naturais e o modelo agrário de produção de alimentos prejudicam a diversidade biológica e cultural, com enorme impacto sócio ambiental negativo (PORTOGONÇALVES, 2004). Aa preocupação com o consumo de alimentos saudáveis e saborosos está aumentando. No entanto, a relação entre seres humanos e alimentos tem características multidimensionais, portanto é necessário levar em consideração a interação entre a forma de produção e os hábitos alimentares para o desenvolvimento de práticas sustentáveis (CASSOL et al., 2015).

Questões centrais no Programa Nacional de Segurança Alimentar e Nutricional (BRASIL, 2016) revelam a relevância a da pesquisa por alimentos não convencionais e inovadores, em busca de alternativas para modelos de produção sustentáveis. Com o tempo, várias escolhas alimentares tornam-se um hábito. No entanto, a alimentação é um processo afetado por vários fatores dinâmicos com constantes mudanças (BRASIL, 2014).

O Brasil possui faixa litorânea extensa, oferecendo uma ampla variedade de recursos naturais (BRASIL, 2008). Algas marinhas podem ser um alimento alternativo, iniciativas em todo o mundo procuram explorar melhor este recurso natural (CARDÓ, 2016). As algas estão sendo empregadas em uma ampla gama de aplicações cosméticas, farmacêuticas e alimentícias. Este último é, na verdade, sua principal utilização (GRAHAM et al., 2009). O valor nutricional também tem produzido crescente interesse em pesquisas devido ao grande número de vitaminas, minerais, proteínas e fibras em sua composição (FAO, 2016). A colheita de macroalgas é uma alternativa de renda para as famílias, dependendo da pesca artesanal, especialmente quando as mulheres participam da atividade (MARINHO-SORIANO, 2016). Apesar da vasta literatura sobre potenciais nutricionais, poucos estudos foram publicados sobre o uso de macroalgas em alimentos. 
Um projeto desenvolvido pela Organização das Nações Unidas para Alimentação e Agricultura (FAO), entre 2001 e 2003, revelou a viabilidade do cultivo de macroalgas Gracilaria em comunidades dos estados do Ceará, Paraíba e Rio Grande do Norte (REBOURS et al., 2014). Quando se consideram os ensaios em andamento e o conhecimento acumulado sobre o cultivo e o processamento de macroalgas por comunidades litorâneas da região nordeste do Brasil, estudos sobre alimentos produzidos utilizando este recurso natural pode ajudar a agregar valor.

Bolos são alimentos de baixo custo preparados por técnicas simples. A adição de macroalgas em alimentos habituais pode ser uma alternativa e facilitar o seu consumo. Os atributos sensoriais são muito relevantes para o gosto ou não gosto de alimentos, pois várias sensações são produzidas no ato de degustação por meio de reações fisiológicas e subjetivas. A avaliação de características organolépticas dos alimentos com a adição de suplementos não usualmente empregados em análises que caracterizam atributos sensoriais, é uma ferramenta que ajuda a medir e analisar sua aceitação e ou rejeição quando comparada a alimentos tradicionais. A análise sensorial é um método científico usado para medir, interpretar e analisar as características organolépticas dos alimentos (ABNT, 1993). Os alimentos são vetores de nutrientes essenciais para a manutenção do organismo humano. A análise centesimal é a melhor forma de demonstrar seu valor nutricional e avaliar a proporção de seus componentes (INSTITUTO ADOLFO LUTZ, 2008). Objetivou-se com esta pesquisa avaliar, analisar e comparar as características sensoriais e o valor nutricional de um bolo preparado com a macroalga Gracilaria birdiae com um bolo tradicional.

\section{MATERIAIS E MÉTODOS}

O projeto foi submetido e aprovado CAAE: 67259317.4.0000.5537 pelo Comitê de Ética em Pesquisa (CEP) da Universidade Federal do Rio Grande do Norte (UFRN), órgão registrado no Comitê Nacional de Ética em Pesquisa (CONEP). Para realização desta pesquisa, a macroalga Gracilaria birdiae foi obtida a partir do cultivo realizado pela Associação de Maricultura e Beneficiamento de Algas (AMBAP) na Praia de Pitangui, Município de Extremoz, Litoral Oriental do Estado do Rio Grande do Norte, localizada entre as coordenadas Latitude: 05 42’ 20" Sul Longitude: 35 18' 26" Oeste. As macroalgas são colhidas, higienizadas, desidratadas ao sol, embaladas e rotuladas em pacotes contendo $50 \mathrm{~g}$. Os demais ingredientes foram adquiridos em estabelecimentos comerciais na cidade de Natal, Rio Grande do Norte (RN).

Baseado nas práticas já desenvolvidas pela AMBAP na produção de alimentos utilizando a macroalga Gracilaria birdiae, testes preliminares foram realizados no Laboratório de Controle de Qualidade de Alimentos da Escola Agrícola de Jundiaí, Unidade Especializada em Ciências Agrárias da Universidade Federal do Rio Grande do Norte, EAJ/UFRN, sendo sistematizada a receita de um bolo controle, a partir do qual foi produzido o bolo adicionado da macroalga $G$. birdiae (Tabela 1) seguindo rigorosamente a mesma sequência de processos.

Os experimentos foram conduzidos de acordo com as normas de segurança, higiene e boas práticas de manipulação de alimentos estabelecidas pela Agência Nacional de Vigilância Sanitária - ANVISA (BRASIL, 2004). As receitas foram preparadas individualmente com técnica padrão através dos seguintes processos: 
pré-aquecimento do forno a $180^{\circ} \mathrm{C}$, separação dos ingredientes e pesagem em balança digital (Filizola ${ }^{\circ}$, Brasil) com precisão de $0,1 \mathrm{~g}$; formas untadas com recobrimento de toda superfície da forma com manteiga e farinha de trigo; trituração das macroalgas em liquidificador de uso doméstico; bateção da manteiga, os ovos e o açúcar por aproximadamente 10 (dez) minutos em batedeira planetária; adição da farinha de trigo peneirada com mistura manual com auxílio de espátula até homogeneização, acréscimo do leite com mistura manual até homogeneização, finalizar com o fermento e a essência de baunilha.

Tabela 1: Composição das amostras de bolo controle e de bolo G. birdiae $e^{(1)}$

\begin{tabular}{|l|l|l|}
\hline \multicolumn{1}{|c|}{ INGREDIENTES } & \multicolumn{2}{c|}{ AMOSTRAS } \\
\hline Farinha de trigo & bolo controle & bolo G. birdiae \\
\hline Açúcar cristal & $280 \mathrm{~g}$ & $280 \mathrm{~g}$ \\
\hline Manteiga integral sem sal & $200 \mathrm{~g}$ & $200 \mathrm{~g}$ \\
\hline Leite integral & $80 \mathrm{~g}$ & $80 \mathrm{~g}$ \\
\hline Fermento químico & $280 \mathrm{~mL}$ & $280 \mathrm{~mL}$ \\
\hline Ovo & $10 \mathrm{~g}$ & $10 \mathrm{~g}$ \\
\hline Essência de baunilha & $135 \mathrm{~g}$ & $135 \mathrm{~g}$ \\
Preparado de G. Birdiae & $5 \mathrm{~mL}$ & $5 \mathrm{~mL}$ \\
\hline
\end{tabular}

(1): não contém.

Tabela 2: Composição do preparado de G. Birdiae.

\begin{tabular}{|l|l|l|}
\hline INGREDIENTES & & \\
\hline Água & $150 \mathrm{~mL}$ & \\
\hline G. birdiae seca & $15 \mathrm{~g}$ & \\
\hline
\end{tabular}

Para o bolo $G$. birdiae seguir os mesmos procedimentos, porém antes da finalização da massa fazer a confecção do preparado $G$. birdiae (Tabela 2) com a colocação da água e da macroalga em panela levando ao fogo até o ponto de fervura, na sequência transferência para o copo do liquidificador e fazer bateção desta mistura, adicionar à massa juntamente com o fermento e a essência de baunilha. Acondicionamento da massa em forma untada e forneamento por 40 (quarenta) minutos, aguardou-se o resfriamento da massa a temperatura ambiente para desenformar.

A aplicação dos testes sensoriais com o bolo controle e o bolo G. birdiae ocorreu em outubro de 2017 no Laboratório de Análise Sensorial localizado no Departamento de Nutrição da Universidade Federal do Rio Grande do Norte, Natal, DNUT/UFRN. A divulgação e convite para participação nos testes foi feita através de cartazes fixados no prédio do DNUT/UFRN. Para selecionar os participantes e explicar melhor os objetivos da pesquisa, além de garantir que o direito dos julgadores seriam respeitados e pedir o consentimento de sua participação, antes da aplicação dos testes sensoriais foi solicitado aos provadores a leitura, o preenchimento e a assinatura do Termo de Consentimento Livre e Esclarecido (TCLE). Também foi aplicado um questionário com a intenção de coletar informações sobre a idade, gênero, nível de escolaridade dos participantes e para detectar intolerância ou reação alérgica a lactose e/ou proteínas do leite e/ou ao glúten, nestes casos a participação era imediatamente interrompida.

Participaram dos testes 59 julgadores voluntários e não treinados. A degustação foi realizada em cabines individuais com acesso independentemente do local de preparo das amostras. Os bolos foram preparados no dia da análise considerando as boas práticas de manipulação e armazenamento de alimentos. As amostras foram servidas a temperatura ambiente, padronizadas em porção de $15 \mathrm{~g}$, acondicionadas em 
copinhos descartáveis de $50 \mathrm{ml}$ codificados aleatoriamente. Para realização da análise sensorial foram utilizados o método sensorial discriminativo com a aplicação do Teste Duo-Trio e o método sensorial afetivo aplicado através do Teste de Aceitação com escala hedônica. A partir dessas avaliações foram verificados se existe diferença entre as amostras, o índice de aceitação e a intenção de compra.

O Teste Duo-Trio foi aplicado com o intuito de verificar se existe diferença significativa $(p<0,05)$ entre as amostras. Cada avaliador recebeu uma bandeja contendo a ficha de avaliação, três amostras de bolo, sendo uma referência e duas codificadas, copo com água e bolacha cream cracker. Metade dos provadores receberam como referência a amostra de bolo controle e metade receberam bolo G. birdiae, uma das codificadas era igual a referência e a outra era diferente. $O$ provador foi orientado a degustar primeiro a amostra referência e na sequência as amostras codificadas, sendo uma delas igual a referência e a outra diferente. $\mathrm{O}$ julgador também foi orientado a ingerir entre uma amostra e outra à água e a bolacha cream cracker para limpar o palato. Foi solicitado ao avaliador preencher a ficha indicando qual a amostra era idêntica a referência. As amostras foram servidas em posições aleatórias definidas por sorteio (DUTCOSKY, 2013).

Na sequência o mesmo provador recebeu outra bandeja com mais duas amostras, bolo controle e bolo G. birdiae apresentadas de forma aleatória, ficha de avaliação, copo com água, bolacha cream cracker e as mesmas orientações para limpar o palato, sendo aplicado o Teste de Aceitação para avaliação dos atributos sensoriais odor, sabor, textura e aparência global, os avaliadores classificaram cada atributo das diferentes amostras através de escala hedônica conforme os seguintes escores: ( 9 = gostei extremamente, 8 = Gostei muito, 7 = Gostei moderadamente, 6 = Gostei ligeiramente, $5=$ Indiferente, $4=$ Desgostei ligeiramente, 3 = Desgostei moderadamente, 2 = Desgostei muito, 1 = Desgostei extremamente).

Para verificar a aceitação das amostras pelos avaliadores, calculou-se o índice de aceitação (IA) para cada atributo sensorial de acordo com (Teixeira et al., 1987): IA(\%) $=\mathrm{Y} \times 100 / Z$, onde $Y=$ nota média obtida para o alimento e $Z$ = nota máxima dada ao alimento. Para estimar a intenção de compra das diferentes amostras apresentadas, utilizou-se escala hedônica de cinco pontos com os seguintes escores: $(5$ = não compraria, $4=$ compraria raramente, $3=$ compraria ocasionalmente, $2=$ compraria frequentemente, $1=$ compraria sempre).

As análises para determinação da composição centesimal (umidade, cinzas, lipídeos, proteínas, fibras, carboidratos e valor calórico total) da macroalga G. birdiae desidratada, do bolo controle e de do bolo G. birdiae, foram realizadas no Laboratório de Bromatologia, localizado no Departamento de Farmácia da Universidade Federal do Rio Grande do Norte, Natal, RN. As amostras foram trituradas e as análises foram realizadas em triplicata para cada componente e os bolos foram analisados separadamente, seguindo a metodologia descrita em Instituto Adolfo Lutz (2008). O teor de umidade foi determinado pelo método de secagem em estufa 105으 (cento e cinco graus Celsius) até atingir peso constante. Para determinação das cinzas as amostras passaram por completa carbonização em mufla a 505으 (quinhentos e cinco graus Celsius), até atingir coloração branca acinzentada obtendo um resíduo isento de carvão. Os lipídeos foram determinados pelo teor de substâncias solúveis em éter etílico, através de aparelho soxhelt. O nitrogênio foi 
determinado pelo método Kjeldahl, então para calcular o do teor de proteína o valor total de nitrogênio foi multiplicado por 6,25. Para determinar quantidade de carboidrato somaram-se os números correspondentes as porcentagens das cinco determinações precedentes (umidade, cinza, lipídeos, proteína e fibra) e diminuiuse o número obtido de 100. Esta diferença corresponde ao valor da fração NIFEXT para 100 gramas de amostra. O valor calórico foi obtido por meio de cálculo teórico considerando a soma das quantidades de calorias provenientes das proteínas, dos carboidratos e dos lipídeos, utilizando-se os seguintes fatores: $4 \mathrm{kcal} / \mathrm{g}$ de proteínas, $4 \mathrm{kcal} / \mathrm{g}$ de carboidratos e $9 \mathrm{kcal} / \mathrm{g}$ de lipídeos. 0 valor foi expresso em $\mathrm{kcal} / 100 \mathrm{~g}$ da amostra.

Para a análise estatística o número de respostas corretas obtidas na aplicação do Teste Duo-Trio foi comparado com a tabela dada em Astm (2008), que demonstra que se o número de respostas corretas é maior ou igual ao valor tabelado, pode-se concluir que existe diferença estatística significativa entre as amostras. Se o número de respostas corretas é menor que o valor tabelado, conclui-se que as amostras são suficientemente similares.

Os dados obtidos na avaliação dos atributos sensoriais, intenção de compra e análise centesimal foram inicialmente submetidos ao teste de normalidade de Shapiro Wilks e uma vez constatada a distribuição não paramétrica dos mesmos, aplicou-se o teste de Kruskal-Wallis. Em caso de constatação de diferenças significativas, utilizou-se o teste pos hoc de $T$ de Student. Os dados foram processados através da utilização do programa ' $R$ '. Para avaliação dos resultados foi adotado o nível de significância $p<0,05$.

\section{RESULTADOS}

Dentre os 59 provadores voluntários não treinados que participaram da análise sensorial, 83,1\% eram do gênero feminino e $16,9 \%$ do gênero masculino, com $93,2 \%$ do total de participantes abrangendo faixa etária entre 18 a 30 anos e 3,4\% para as faixas etárias entre 31 a 40 e 41 a 50 anos respectivamente. Em relação ao nível de escolaridade dos participantes, 83,5\% cursavam graduação, 9,9\% ensino médio, 4,9\% ensino técnico e $1,7 \%$ cursavam pós graduação.

Com base nas respostas obtidas na aplicação do Teste Duo-Trio, foi identificado que dos cinquenta e nove (59) participantes, apenas trinta e um (31) dos provadores identificaram qual a amostra codificada correspondia à referência (bolo controle), vinte e oito (28) não identificaram. De acordo com a metodologia utilizada (ASTM, 2008) o número de respostas corretas (31) é menor que o valor tabelado (35), demonstrando que as amostras são suficientemente similares.

Tabela 3: Escores $^{(1)}$ e Índice de Aceitação para os atributos sensoriais das amostras de biscoito controle e biscoito $G$. birdiae.

\begin{tabular}{|l|l|l|l|l|l|l|l|l|}
\hline & & & & Atributos & & & & \\
\hline & Odor & & Sabor & & Textura & & Aparência global & \\
\hline Amostras & Escore & IA (\%) & Escore & IA (\%) & Escore & IA (\%) & Escore & IA (\%) \\
\hline Bolo controle & $7,78^{\mathrm{a}} \pm 1,13$ & 84,56 & $7,78^{\mathrm{a}} \pm 1,16$ & 86,44 & $8,00^{\mathrm{a}} \pm 1,17$ & 88,89 & $7,88^{\mathrm{a}} \pm 1,26$ & 87,57 \\
Bolo com G. birdiae & $6,42^{\mathrm{a}} \pm 1,48$ & 82,49 & $7,45^{\mathrm{a}} \pm 1,36$ & 82,86 & $6,68^{\mathrm{b}} \pm 1,96$ & 74,20 & $6,93^{\mathrm{b}} \pm 1,56$ & 76,65 \\
\hline
\end{tabular}

${ }^{(1)}$ média \pm desvio padrão. Letras diferentes na mesma coluna denotam diferenças estatísticas (teste $t$ Student); IA (\%) = Índice de Aceitação. 
Tabela 4: Escores para intenção de compra(1) para as amostras de bolo controle e bolo com G. birdiae.

\begin{tabular}{|l|l|}
\hline Amostras & IC \\
\hline Bolo controle & $2.49^{\mathrm{a}} \pm 1.05$ \\
Bolo com G. birdiae & $3.15^{\mathrm{b}} \pm 1.27$ \\
\hline
\end{tabular}

${ }^{(1)}$ média \pm desvio padrão, escala hedônica de cinco pontos. Letras diferentes na mesma coluna denotam diferenças estatísticas (teste $t$ Student);

Table 5: Composição centesimal (\%) ${ }^{(1)}$ de G. birdiae in natura e G. birdiae desidratada.

\begin{tabular}{|c|c|c|}
\hline Centesimal composition & G. birdiae in natura & Dehydrated G. birdiae \\
\hline Humidity & $90.508^{a} \pm 0.11$ & $0.050^{\mathrm{b}} \pm 0.00$ \\
\hline Ashes & $4.283^{a} \pm 0.18$ & $5.978^{a} \pm 0.08$ \\
\hline Lipids & $0.350^{\mathrm{a}} \pm 0.04$ & $2.377^{a} \pm 0.54$ \\
\hline Fibers & $1.066^{\mathrm{a}} \pm 0.24$ & $11.090^{\mathrm{a}} \pm 2.50$ \\
\hline Proteins & $0.665^{a} \pm 0.02$ & $8.750^{\mathrm{a}} \pm 0.96$ \\
\hline Carbohydrates & $3.196^{\mathrm{a}} \pm 0.36$ & $72.937^{b} \pm 2.24$ \\
\hline Total calorie rate $(\mathrm{TVR})^{(2)}$ & $18.395^{\mathrm{a}} \pm 1.17$ & $343.476^{a} \pm 12.76$ \\
\hline
\end{tabular}

${ }^{(1)}$ mean \pm standard deviation. Different letters in the same column means statistical differences (Student's $t$ test); ${ }^{(2)}$ Total Calorie Rate.

Table 6: Centesimal composition (\%) ${ }^{(1)}$ of samples of control cake and cake supplemented with G. birdiae.

\begin{tabular}{|l|l|l|}
\hline Centesimal composition & Control cake & Cake supplemented with birdiae \\
\hline Humidity & $32.547^{\mathrm{a}} \pm 0.17$ & $35.563^{\mathrm{a}} \pm 0.19$ \\
\hline Ashes & $0.502^{\mathrm{a}} \pm 0.02$ & $0.529^{\mathrm{a}} \pm 0.02$ \\
\hline Lipids & $3.567^{\mathrm{a}} \pm 0.19$ & $1.224^{\mathrm{a}} \pm 0.25$ \\
\hline Fibers & $2.791^{\mathrm{a}} \pm 0.75$ & $1.224^{\mathrm{b}} \pm 0.25$ \\
\hline Proteins & $2.078^{\mathrm{a}} \pm 0.17$ & $1.831^{\mathrm{b}} \pm 0.08$ \\
\hline Carbohydrates & $58.473^{\mathrm{a}} \pm 0.92$ & $57.168^{\mathrm{b}} \pm 0.33$ \\
\hline TCR & $274.475^{\mathrm{a}} \pm 1.53$ & $269.646^{\mathrm{a}} \pm 1.92$ \\
\hline \\
(1) mean \pm standard deviation. Different letters in the same column means statistical differences (Student's $t$ test); ${ }^{(2)}$ Total \\
Calorie Rate.
\end{tabular}

\section{DISCUSSÃO}

A aplicação do Teste de Aceitação mostrou que os atributos sensoriais cheiro e sabor não apresentaram diferenças significativas $(p<0,05)$ entre as amostras (Tabela 3). Embora tenha havido diferença significativa $(p<0,05)$ para os atributos textura e aparência global entre as amostras, Olfato e paladar são as características mais importantes em produtos alimentícios preparados a partir de ingredientes pouco utilizados em sua produção (ALAMANOU, 1996).

O índice de aceitação (IA) (Tabela 3) foi calculado a partir dos escores médios de cada atributo (Tabela 3), com positividade para as duas amostras. Segundo (TEIXEIRA et al., 1987; DUTCOSKY, 2013), alimentos com pelo menos $70 \%$ de índice de aceitação deve ser sensorialmente aceito. A Tabela 4 mostra que o bolo controle teve uma diferença significativa $(p<0,05)$ quando comparado ao bolo adicionado de $G$. birdiae, com médias entre 2 - compraria o produto com freqüência, e 3 - poderia comprar produto; o bolo adicionado com G. birdiae apresentou médias entre 3 - compraria ocasionalmente e 4 - raramente compraria o produto. De acordo com (GUERRERO et al., 2000), a intenção de compra pode ser afetada por vários fatores, como preço, marketing e dados sobre o produto, embora as características sensoriais do alimento determinem a escolha do consumidor. A análise estatística dos dados da análise centesimal da espécie in natura e desidratada G. birdiae revelou uma diferença significativa ao nível de $5 \%$ de probabilidade para componentes umidade e carboidratos (Tabela 5). 
No presente estudo, a macroalga desidratada G. birdiae continha 8,75\% de proteínas, similar (7,1\%) à de (GRESSLER et al., 2011) para as mesmas macroalgas. Os autores confirmaram que as análises com algas são frequentes na busca de fontes com suplementos protéicos. Apesar de resultados semelhantes, as macroalgas, mesmo aquelas da mesma espécie, podem apresentar composição centesimal diferente, uma vez que são afetadas pelo ambiente e pelas estações do ano (BENJAMA et al., 2011; WELLS et al., 2016). Os resultados das amostras de G. birdiae mostram taxas de nutrientes significativas em relação às plantas terrestres. As taxas de proteína e cinzas (respectivamente 8,75\% e 5,98\%) em G. birdiae desidratada no presente estudo devem ser destacadas. De fato, quando foram comparadas às taxas sob a seção vegetais e derivados da Lista Brasileira de Composição de Alimentos (TACO) (UNICAMP, 2011), apenas as folhas desidratadas de coentro tiveram as maiores taxas em proteínas (20,9\%) e cinzas (10,2\%).

No caso de amostras de bolo, ocorreu diferença significativa a $5 \%$ de probabilidade para os componentes fibras, proteínas, carboidratos e valor calórico total (Tabela 6). Como não há referências para a produção de bolos suplementados com macroalgas, a diminuição nas taxas nutricionais de fibras, proteínas, carboidratos e calorias totais deve-se, provavelmente, ao método de preparo utilizado para a suplementação de macroalgas $\mathrm{G}$. birdiae aos bolos. massa.

\section{CONCLUSÕES}

Dentro das condições estudadas, ficou demonstrado que a adição da macroalga Gracilaria birdiae em bolos é possível, pois os resultados sensoriais são satisfatórios. No entanto, a composição centesimal do bolo sugeriu que além da adição de novos ingredientes, o método de preparo escolhido e a quantidade utilizada pode influenciar no enriquecimento ou não de alimentos, sugerindo reflexões para realização de testes futuros na busca por resultados satisfatórios.

\section{REFERÊNCIAS}

ABNT. Associação Brasileira de Normas Técnicas. 1993. ABNT NBR 12806: Análise sensorial de alimentos e bebidas. Rio de Janeiro: ABNT.

ALAMALOU, S.; BLOUKAS, J. G.; PANERAS, E. D.; DOXASTAKIS, G.. Influence of protein isolate from lupin seeds (Lupinus albus ssp. Graecus) on processing and quality characteristics of frankfurters. Meat Science, v.42, n.1, p.7993, 1996.

ASTM. American Society for Testing and Materials. ASTM E 2610-08: Standard test method for sensory analysis: duo trio test. West Conshohocken. 2008.

BARBOSA, G. S.; DRACH, P. R.; CORBELLA, O. D. A. Conceptual Review of the Terms Sustainable Development and Sustainability. International Journal of Social Sciences, v.3, n.2, 2014.

BENJAMA, O.; MASNIYOM, P.. Nutritional composition and physicochemical properties of two green seaweeds (Ulva pertusa and $U$. intestinalis) from the Pattani Bay in Southern Thailand. Songklanakarin J. Sci. Technol., v.33, n.5, p.575583. 2011.
BRASIL. Ministério da Saúde. Agência Nacional de Vigilância Sanitária. Resolução de Diretoria Colegiada n.216: Regulamento de Boas Práticas para Serviços de Alimentação. Brasília: DOU, 2004.

BRASIL. Ministério do Meio Ambiente. Áreas prioritárias para conservação, uso sustentável e repartição de benefícios da biodiversidade brasileira. Brasília: Ministério do Meio Ambiente, 2008.

BRASIL. Ministério da Saúde. Secretaria de Atenção à Saúde. Política Nacional de Alimentação e Nutrição. Brasília: Ministério da Saúde, 2012.

BRASIL. Ministério da Saúde. Secretaria de Atenção à Saúde. Guia alimentar para a população brasileira. 2 ed. Brasília: Ministério da Saúde, 2014.

BRASIL. Câmara Interministerial de Segurança Alimentar e Nutricional. Plano Nacional de Segurança Alimentar e Nutricional: PLANSAN. 2016/2019. Brasília, 2016. 
CARDÓ, N. C.. Algas marinhas para la alimentación de los peruanos. Turismo y Patrimônio, v.10, p.55-68, 2016.

CASSOL, A.; SCHENEIDER, S.. Produção e consumo de alimentos: novas redes e atores. Lua Nova, Revista de Cultura e Política, v.95, p.143-180. 2015. DOI: http://dx.doi.org/10.1590/0102-6445143-177/95

CONTE, I. I.; BOFF, L. A.. As crises mundiais e a produção de alimentos no Brasil. Acta Scientiarum: Human and Social Sciences, v.35, n.1, p.49-59. 2013.

DUTCOSKY, S. D.. Análise sensorial de alimentos. 4 ed. Curitiba: Champagnat, 2013

GRAHAM, L. E.; GRAHAM, L. W.; WILCOX, L. W.. Algae. 2 ed. São Francisco: Pearson, 2009.

GRESSLER, V.; YOKOYA, N. S.; FUJI, M. T.; COLEPICOLO, P.; FILHO, J. M.; TORRES, R. P.; PINTO, E.. Lipds, fatty acids, protein, amino acid and ash contents in four Brazilian red algae species. Food Chemistry, v.120, n.2, p.585-590. 2010.

GUERRERO, L.; COLOMER, Y.; GUÀRDIA, M. D.; XICOLA, J.; CLOTET, R.. Consumer attitude towards store brands. Food Quality and Preference, v.11, n.6, p.387-395 2000. DOI: http://dx.doi.org/10.1016/S0950-3293(00)00012-4

\section{INSTITUTO ADOLFO LUTZ. Normas analíticas do Instituto}

Adolfo Lutz: métodos físico-químicos para análise se alimentos. 4 ed. São Paulo: Instituto Adolfo Lutz, 2008.

KINUPP, V. F.; LORENZI, H.. Plantas alimentícias não convencionais (PANC) no Brasil: Guia de identificação, aspectos nutricionais e receitas ilustradas. Nova Odessa: Instituto Plantarum, 2014.
MALLMAN, L. D.; JAHNO, V. D.. As diversas aplicações de algas marinhas através dos saberes populares visando a utilização sustentável. Revista Ambientalmente Sustentable, v.2, n.20, p.1841-1856, 2015. DOI: http://doi10.17979/ams.2015.2.20.1702

MARINHO-SORIANO, E.. Historical context of commercial exploitation of seaweeds in Brazil. Journal of Applied Phycology, v.29, n.2, p.665-671. 2016. DOI: http://doi10.1007/s10811-016-0866-8

PORTO-GONÇALVES, C. W.. Desafio ambiental: os porquês da desordem mundial. Rio de Janeiro: Record, 2004.

REBOURS, C.; MARINHO-SORIANO, E.; ZERTUCHE-GONZALES, A. J.; HAYASHI, L.; VASQUEZ, A. J.; KRADOULFER, P.; SORIANO, G.; UGARTE, R.; ABREU, H. M.; BAY-LARSEN, I.; HOVELSRUD, G.; RODVEN, R.; ROBLEDO, D.. Seaweeds: an opportunity for wealth and sustainable livelihood for coastal communities. Journal of Applied Phycology, v.26, p.19391951, 2014. DOI: http://dx.doi.org/10.1007/s10811-0140304-08

UNICAMP. Núcleo de Estudos e Pesquisas em Alimentação. Tabela brasileira de composição de alimentos: TACO. 4 ed. Campinas: Universidade Estadual de Campinas, 2011.

WELLS, M. L.; POTIN, P.; CRAIGIE, J. S.; RAVEN, J. A.; MERCHANT, S. S.; HELLIWELL, K. E.; SMITH, A. G.; CAMIRE, M. E.; BRAWLEY, S. H.. Algae as nutritional and functional food sources: revisiting our understanding. Journal of Applied Phycology, v.29, n.2, p.949-982, 2017. DOI: http://dx.doi.org/10.1007/s10811-016-0974-5

A CBPC - Companhia Brasileira de Produção Científica (CNPJ: 11.221.422/0001-03) detém os direitos materiais desta publicação. Os direitos referem-se à publicação do trabalho em qualquer parte do mundo, incluindo os direitos às renovações, expansões e disseminações da contribuição, bem como outros direitos subsidiários. Todos os trabalhos publicados eletronicamente poderão posteriormente ser publicados em coletâneas impressas sob coordenação da Sustenere Publishing, da Companhia Brasileira de Produção Científica e seus parceiros autorizados. Os (as) autores (as) preservam os direitos autorais, mas não têm permissão para a publicação da contribuição em outro meio, impresso ou digital, em português ou em tradução. 